\title{
Relationships between components of emotional intelligence and physical pain in alcohol-dependent patients
}

\author{
Maciej Kopera' \\ Kirk J Brower ${ }^{2}$ \\ Hubert Suszek ${ }^{3}$ \\ Andrzej Jakubczyk' \\ Sylwia Fudalej' \\ Aleksandra Krasowska' \\ Anna Klimkiewicz' \\ Marcin Wojnar ${ }^{1,2}$ \\ 'Department of Psychiatry, Medical \\ University of Warsaw, Warsaw, \\ Poland; '2Department of Psychiatry, \\ Addiction Research Center, University \\ of Michigan, Ann Arbor, MI, USA; \\ ${ }^{3}$ Department of Psychology, University \\ of Warsaw, Warsaw, Poland
}

This article was published in the following Dove Press journal:

Journal of Pain Research

II July 2017

Number of times this article has been viewed
Purpose: Chronic pain is a significant comorbidity in individuals with alcohol dependence (AD). Emotional processing deficits are a substantial component of both $\mathrm{AD}$ and chronic pain. The aim of this study was to analyze the interrelations between components of emotional intelligence and self-reported pain severity in AD patients.

Patients and methods: A sample of 103 participants was recruited from an alcohol treatment center in Warsaw, Poland. Information concerning pain level in the last 4 weeks, demographics, severity of current anxiety and depressive symptoms, as well as neuroticism was obtained. The study sample was divided into "mild or no pain" and "moderate or greater pain" groups. Results: In the logistic regression model, across a set of sociodemographic, psychological, and clinical factors, higher emotion regulation and higher education predicted lower severity, whereas increased levels of anxiety predicted higher severity of self-reported pain during the previous 4 weeks. When the mediation models looking at the association between current severity of anxiety and depressive symptoms and pain severity with the mediating role of emotion regulation were tested, emotion regulation appeared to fully mediate the relationship between depression severity and pain, and partially the relationship between anxiety severity and pain. Conclusion: The current findings extend previous results indicating that emotion regulation deficits are related to self-reported pain in AD subjects. Comprehensive strategies focusing on the improvement of mood regulation skills might be effective in the treatment of AD patients with comorbid pain symptoms.

Keywords: mood regulation, pain, alcoholism, emotional regulation

\section{Introduction}

According to the American Society of Addiction Medicine, "dysfunctional emotional response," along with cognitive function impairments, is a key feature of addiction. Deficits in emotional processing including emotion recognition, labeling,,$^{1,2}$ and alexithymia ${ }^{3}$ have been reported in various alcohol-dependent (AD) samples. Difficulties in the identification and description of one's own emotional state, together with impairments in perception and labeling of emotion displayed by others, may represent a complex emotion-processing deficit in this clinical group. The aforementioned competencies are implied as one of the basic constituents of emotional intelligence (EI). EI has been defined 4 as a compound of emotional skills or traits that includes: "the ability to perceive accurately, appraise, and express emotion; the ability to access and/ or generate feelings when they facilitate thought; the ability to understand emotion and emotional knowledge; and the ability to regulate emotions to promote emotional and intellectual growth". Preliminary data suggest that individuals with AD also have
Correspondence: Sylwia Fudalej Department of Psychiatry, Medical University of Warsaw, 27 Nowowiejska St., 00-665 Warsaw, Poland

$\mathrm{Tel}+4822825 \quad 1236$

$\mathrm{Fax}+48228251315$

Email sylwia.fudalej@wum.edu.pl 
lower EI; however, there is still not enough clinical data coming from $\mathrm{AD}$ population to make unequivocal conclusions. ${ }^{5,6}$ Of importance, limited data show that emotion-processing deficits may be associated with adverse outcomes in AD samples. Deficits in utilization of emotions predicted poorer post-treatment outcomes in a recent study of those treated for AD. ${ }^{7}$ In another study, poor emotion-regulation skills in AD samples predicted post-treatment alcohol use at 3-month follow-up. ${ }^{8}$

Pain is commonly comorbid with alcohol use disorders (AUDs). ${ }^{9,10}$ National surveys have revealed that AD is approximately twice as likely to occur among individuals with chronic pain. ${ }^{9,10}$ In clinical samples, more than $40 \%$ of patients treated for chronic pain met criteria for an AUD. ${ }^{11}$ Conversely, between $18 \%$ and $38 \%$ of patients who participated in various addiction treatment programs in the USA reported at least moderately severe pain in the last 12 months. ${ }^{12}$ Despite the importance of understanding the intersection between pain and alcohol use, only limited work has been carried out in this area and most of this has been done from a neurobiological perspective. Of clinical importance, pain is a predictor of poor drug- and alcohol-related outcomes in those treated for addictive disorders, including AUDs, ${ }^{12,13}$ and self-reported decrease in pain following treatment for $\mathrm{AD}$ is associated with a lower risk of alcohol relapse. ${ }^{14}$

Several explanations for the prevalent co-occurrence of AUD and chronic pain have been proposed. It has been postulated that comorbidity of pain and AUD may be explained by recursive, partly shared, neural systems. In this context, pain is conceptualized as a disorder of reward function ${ }^{15}$ sharing pathophysiological mechanisms with addictions. ${ }^{16}$ Biologically, a strong evidence of overlapping neurocircuitry, underlying pain and addiction, led Egli et $\mathrm{al}^{17}$ to argue that AUD could be conceptualized as either a chronic pain disorder or a type of chronic emotional pain syndrome (p. 449). ${ }^{18}$

Among the psychological mechanisms that influence pain, ${ }^{19}$ a significant role for emotional processes has been affirmed. ${ }^{20-22}$ It is acknowledged that pain can be derived solely from emotional or social sources in the absence of nociception. ${ }^{16}$ Neurobiological data indicate reciprocal interactions between pain and emotions. ${ }^{23,24}$ Numerous studies highlight interactions between pain and stress, pain and negative affect, pain and alexithymia, and broadly defined emotional regulation processes and pain. ${ }^{21,24,25}$ Such studies also demonstrate the modulating effect of negative emotions on pain intensity. ${ }^{26-29}$ Moreover, chronic pain can elicit ineffective coping strategies and physical and psychosocial disability, leading to reduced quality of life ${ }^{30}$ and depressive or anxiety symptoms. It has been consistently reported that more than $50 \%$ of chronic pain patients also manifest clinical symptoms of depression. ${ }^{31,32}$ Wiech and Tracey ${ }^{33}$ noted that the relationship between pain and emotions is bidirectional, in that the experiential component of pain aggravates concurrent negative emotions, which then fuels the experience of pain. Studies suggest that individual differences in emotional regulation intervene in this relationship. In a sample of women with rheumatoid arthritis, Hamilton et $\mathrm{al}^{34}$ found that self-reported pain severity varied as a function of emotional intensity and regulation. Women who reported higher emotional intensity and lower ability to regulate their emotions suffered more after a week of increased pain. Likewise, Connelly et $\mathrm{al}^{35}$ found that variability in regulating positive and negative affect was associated with the pain severity in a group of subjects with rheumatoid arthritis. Within the EI framework, Ruiz-Aranda et $\mathrm{al}^{36}$ showed that healthy women, who rated themselves as being more skilled in "emotional repair" (i.e., the ability to use positive thinking to repair negative mood), perceived a standard pain stimulus - induced via the cold-pressor experimental paradigm (CPT) - as less painful than did women who self-reported lower skills. In another study from this group, ${ }^{37}$ participants with higher behaviorally measured EI scores rated pain as both less intense and unpleasant.

Together, the current literature shows that emotional processing deficits are common in both $\mathrm{AD}$ and chronic pain, and may lead to significant adverse outcomes in AD subjects. Moreover, recent data reveal that the two might share a common neurobiological background. ${ }^{38}$ As suggested by LeBlanc et $\mathrm{al}^{38}$ chronic pain and nociceptive hypersensitivity may induce alcohol craving and relapse through alterations in synaptic plasticity within brain reinforcement circuitry. The authors further suggest that pain-induced affective dysregulation in vulnerable individuals may contribute to the transition to addiction. Accordingly, clinical data show that pain syndromes are most commonly diagnosed among psychiatric patients, when reward alterations are also noted. ${ }^{15}$ To the best of our knowledge, there are no data on the relationship between EI and pain severity in a clinical sample of AD individuals. Hence, the purpose of the present study was to explore the relationship between components of EI and self-reported pain severity in AD patients. We also examined whether EI components mediate the relationship between components of negative affect (severity of depression and anxiety) and self-reported pain. We anticipated that EI would make an independent contribution to the prediction of pain severity in this treatment sample. 


\section{Patients and methods \\ Participants}

The study group comprised 103 alcohol-dependent patients entering an 8-week inpatient treatment program in Warsaw, Poland. The study assessments were performed within the first week since admission. Subjects with comorbid severe medical illness, receiving or requiring opioid analgesic therapy, as well as those currently receiving pharmacotherapy for $\mathrm{AD}$, were not admitted to the inpatient treatment program. Similarly, individuals with comorbid psychiatric disorders requiring medication were not admitted to the treatment center. A current diagnosis of AD was established according to the Diagnostic and Statistical Manual of Mental Disorders, 4th ed, Text Revision ${ }^{39}$ criteria during admission and confirmed with the MINI International Neuropsychiatric Interview ${ }^{40}$ by a trained member of the research team. Confirmed abuse or dependence on psychoactive substances other than nicotine and alcohol was exclusionary. All individuals with significant cognitive deficits, scoring $<25$ on the MiniMental State Examination, ${ }^{41}$ as well as patients with a history of psychosis or presence of alcohol withdrawal symptoms, were not eligible to participate.

The study was approved by the Bioethics Committee at the Medical University of Warsaw and the Medical School Institutional Review Board at the University of Michigan. Written informed consent was obtained from all individuals who participated in the study.

\section{Measures}

Sociodemographic characteristics (education, marital status, and employment) were obtained using a modified version of the University of Arkansas Substance Abuse Outcomes Module, a self-administered questionnaire..$^{42}$ A single item from the Polish version of Short Form Health Survey (SF-36) ${ }^{43}$ was included as a measure of physical pain during the past 4 weeks. The question that was asked was, "During the last 4 weeks, how much physical pain did you experience on average?," with the possible responses: 1 - no pain, 2 - very mild pain, 3 - mild pain, 4 - moderate, 5 - strong, and 6 very strong physical pain during the last 4 weeks. Consistent with prior work, ${ }^{12,44,45}$ the responses $1-3$ were subsequently re-coded into a categoric variable "mild or no pain," and responses 4-6 into "moderate or greater pain."

The subscale score for state anxiety from the brief symptom inventory, ${ }^{46}$ depression severity, ${ }^{47}$ and neuroticism (NEO Five-Factor Inventory) ${ }^{48,49}$ were included as a measures of negative affect.
The Schutte Self-Report Emotional Intelligence Test (SSEIT) was utilized as a measure of EI. The most consistently reported factor structure of SSEIT has four factors, which were applied in this study. Factors were calculated and named according to Saklofske et $\mathrm{a}^{50}$ and matched those described by Petrides and Furnham ${ }^{51}$ as follows: appraisal of emotions, mood regulation/optimism, utilization of emotions, and social skills.

\section{Statistical analysis}

In the bivariate analyses, $\mathrm{AD}$ subjects dichotomized by the severity of pain ("mild or no pain" vs "moderate or greater pain") were compared in terms of basic demographic characteristics as well as severity of depressive and anxiety symptoms, neuroticism, and EI components. Analyses of variance (ANOVAs) and chi-square tests tested for differences between the two pain-level groups for continuous and dichotomus variables, respectively. Subsequently, a logistic regression model was applied in order to determine the strongest independent correlates of physical pain in the current $\mathrm{AD}$ sample. To avoid multicollinearity between the affect-related risk factors (EI, depression, anxiety, and neuroticism), a correlation matrix was performed, and intercorrelation values above 0.7 between variables excluded them from further analyses. Controlling for age and gender, all variables that were significantly associated with pain severity in the bivariate analyses were included in the model.

Since it was hypothesized that individual differences in EI would serve as a mediator in the relationship between depression/anxiety and pain severity, two sets of mediation analyses were conducted: one with depression and the other with anxiety being the independent variables. Mediation was tested using the Preacher and Hayes's bootstrapping method with 5,000 resamples with replacement. For this, the SPSS macro suggested by Preacher and Hayes was used. The criterion for statistical significance in all tests (two-tailed) was $p<0.05$. The data were analyzed using statistical package SPSS $^{\circledR} 23.0$ for Windows.

\section{Results}

The study comprised 80 men (77\%) and 23 women (23\%). Their mean $( \pm \mathrm{SD})$ age was $43.57( \pm 11.47)$ years and mean education level was $12.07( \pm 2.82)$ years (the last level of secondary school in Poland). All patients were Caucasian.

ANOVAs looking at associations with self-reported pain levels revealed that patients with moderate/severe physical pain had higher neuroticism scores $(\mathrm{F}=6.79 ; p=0.01)$ and 
Table I Comparison of alcohol-dependent patients with moderate/severe and without or mild physical pain

$\begin{array}{llll} & \text { No/mild physical } & \text { Moderate/severe } \\ \text { pain }(\mathbf{n = 8 0}) & \text { physical pain }(\mathbf{n = 2 3})\end{array}$

Notes: The categorical values are presented as numbers. Parametric variables are presented as mean and standard deviation. $P$-values $<0.05$ are shown in bold.

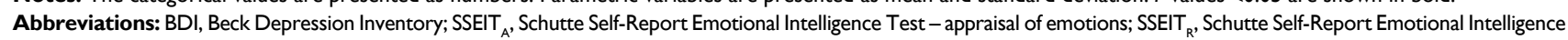
Test - mood regulation; SSEIT, Schutte Self-Report Emotional Intelligence Test - social skills; SSEIT, Schutte Self-Report Emotional Intelligence Test - utilization of emotions.

higher severity of depressive $(\mathrm{F}=5.35 ; p=0.02)$ and anxiety symptoms $(\mathrm{F}=10.93 ; p=0.001)$. Higher pain levels were also associated with lower education $(\mathrm{F}=6.38 ; p=0.01)$. By contrast, subjects who reported no/mild physical pain had higher scores in two of the four EI factors: self-reported mood regulation $(\mathrm{F}=9.60 ; p=0.003)$ and utilization of emotions ( $\mathrm{F}=4.63 ; p=0.03$ ). The detailed comparisons of individuals with moderate/severe physical pain and those with mild or no pain are presented in Table 1.

All variables that were significantly associated with pain levels were entered into a logistic regression analysis. After controlling for age and gender, mood regulation $(\mathrm{OR}=0.83$; 95\% CI: $0.70-0.99 ; p=0.04)$, anxiety severity ( $\mathrm{OR}=2.91$; 95\% CI: $1.11-7.62 ; p=0.03)$, and education $(\mathrm{OR}=0.76$; 95\% CI: $0.59-0.99 ; p=0.04$ ) remained significant predictors of pain severity. The overall model was significant (chi-square $=20.48, d f=8, p=0.009$ ) and explained $30 \%$ of the variance in pain severity (Table 2 ).

\section{Mediation analyses}

It was hypothesized that mood regulation would mediate the effect of both depression and anxiety on pain, thus two sets of mediation analyses were conducted. The first analysis revealed that the indirect effect of depression on pain through mood regulation was significant, with an unstandardized point estimate of 0.03 and a $95 \% \mathrm{CI}$ of $0.002-0.08$. Furthermore, the direct effect of depression on pain $(0.05 ; \mathrm{SE}=0.02$; $p<0.03)$ became nonsignificant when mood regulation was included as a mediator of the direct effect in the model $(0.02$; $\mathrm{SE}=0.03 ; p=0.52$ ). Thus, mood regulation fully mediated the relationship between depression and pain (Figure 1).

The second analysis yielded a significant indirect effect of anxiety on pain through mood regulation $(0.25)$ with a $95 \%$ -confidence interval from 0.04 to 0.66 . Mood regulation only
Table 2 Multivariate model of logistic regression analysis for the prediction of moderate/severe physical pain in alcohol-dependent patients

\begin{tabular}{lll}
\hline & OR (95\% Cl) & p-value \\
\hline SSEIT $_{R}$ & $0.83(0.70-0.99)$ & 0.04 \\
SSEIT $_{U}$ & $1.05(0.78-1.42)$ & 0.75 \\
Age & $1.02(0.96-1.08)$ & 0.56 \\
Gender & $1.78(0.28-4.90)$ & 0.82 \\
Education & $0.76(0.59-0.99)$ & 0.04 \\
Neuroticism & $0.99(0.88-1.12)$ & 0.95 \\
Severity of anxiety symptoms & $2.91(1.11-7.62)$ & 0.03 \\
Severity of depressive symptoms & $0.95(0.88-1.03)$ & 0.21 \\
\hline
\end{tabular}

Notes: Model: $R^{2}$ (Nagelkerke) $=0.31$. Chi-square $=20.48 ; d f=8 ; p=0.009$.

Abbreviations: SSEIT ${ }_{R}$, Schutte Self-Report Emotional Intelligence Test - mood regulation; SSEIT ${ }_{U}$, Schutte Self-Report Emotional Intelligence Test - utilization of emotions.

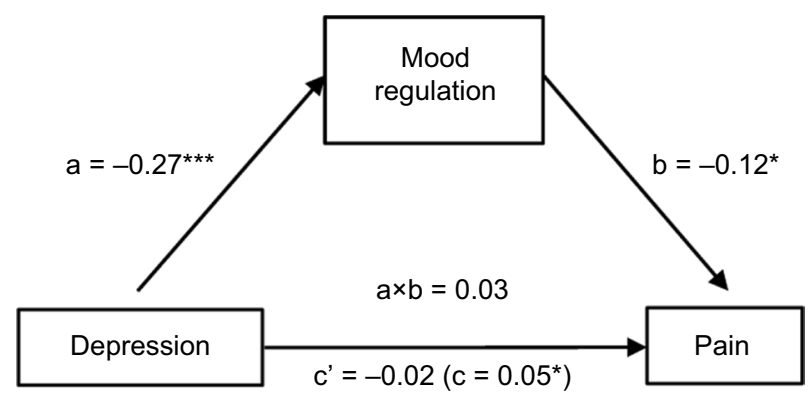

Figure I Mood regulation as a mediator of the relationship between depression and pain.

Notes: The values in the figure are unstandardized path coefficients. ${ }^{*} p<0.05$, and $* * * p<0.001$.

partially mediated the anxiety-pain relationship, as anxiety still had a significant direct effect on pain $(0.75 ; \mathrm{SE}=0.32$; $p<0.02)$, albeit lower than without mood regulation being controlled for $(0.89 ; \mathrm{SE}=0.31 ; p<0.005)$ (Figure 2).

\section{Discussion}

The purpose of our study was to examine how various components of self-reported EI relate to self-reported pain severity in $\mathrm{AD}$ individuals. To our knowledge, this is the first study to 


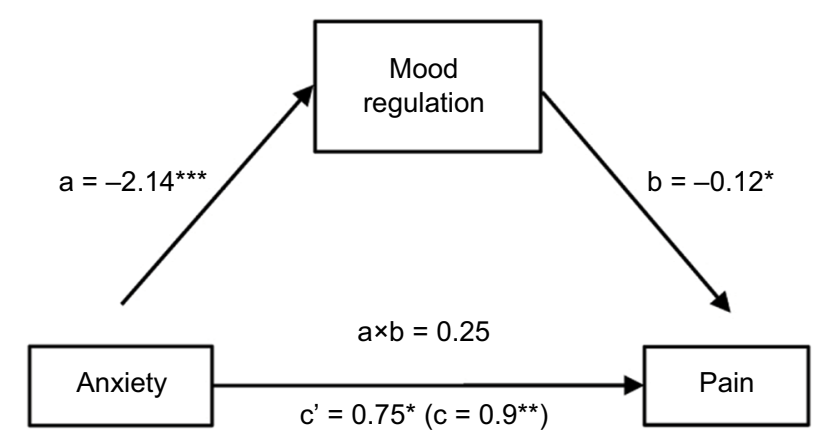

Figure 2 Mood regulation as a mediator of the relationship between anxiety and pain.

Notes: The values in the figure are unstandardized path coefficients. ${ }^{*} p<0.05$, $* * p<0.0$ I, and $* * * p<0.001$.

examine the association between self-reported EI and pain in this clinical population. The study results show that while controlling for negative affect and sociodemographic factors in AD patients, deficits in emotional regulation - a component of EI measured by the SSEIT scale - were a significant correlate of self-reported pain severity during the previous 4 weeks. Utilization of emotions was associated with pain severity before controlling for other variables, but the other two components of EI were not associated with pain. Anxiety and lower education - albeit not depression - were also associated with pain in the multivariate analysis. Education has consistently been shown to be a significant correlate of physical pain severity. ${ }^{52-55}$

The mood regulation factor in the SSEIT scale reflects a person's ability to understand, recognize, and manage his/ her feelings. It measures the capacity to maintain positive feelings on the basis of both previous experiences of doing so and the anticipation and involvement in activities that enhance positive feelings. The better their ability at mood regulation, the easier for individuals to acquire, maintain, and benefit from positive affect.

The study results also revealed that mood regulation fully mediated the relationship between depression and pain, and partially the relationship between anxiety and pain. In other words, greater levels of negative affect (depression or anxiety) were associated with worse emotional regulation skills and more pain. Our results suggest that the self-perceived ability to regulate emotions is a major contributor to the relationship between negative affect and pain. Negative affect may increase the perception of pain, and pain may increase negative affect, but their bidirectional effects depend on emotional regulation competencies in AD patients. These results are consistent with studies in healthy controls and chronic pain populations, focusing on the influence of the negative/positive emotions utilization skills in the pain-affect relationship..$^{35,56-60}$
The results of our study are in line with observations that emotional traits and abilities are associated with selfreported pain severity in chronic pain patients as well as pain-free participants. ${ }^{34,36,37,61}$ In addition, the results of the previous studies reveal that with the changing emotional state (negative or positive affect), pain sensitivity, and perception changes accordingly, depending on the valence of the emotion induced. ${ }^{62,63,21}$ Studies on the effects of mood induction (positive, negative, or neutral) in pain-free participants show that the induction of negative mood results in a significant decrease in CPT pain tolerance, whereas the effect is reversed for the positive mood induction condition. ${ }^{64}$ Importantly, increased positive affect weakens the association between negative affect and pain. ${ }^{57-60}$ This finding has been corroborated by longitudinal observations showing that pain reduction is predicted by increases in positive and decreases in negative affect. ${ }^{35,56}$ Conversely, pain can lead to long-lasting negative emotions, with the modulating effect of individual personality characteristics or previous reflection related to pain experience referred to as "secondary pain affect." 65 Chronic "unspecific" pain may itself be considered a form of masked depression. ${ }^{66}$ Through its relationship to aggravated depressive symptoms, pain increased the probability of depression recurrence. ${ }^{67}$ Across studies, patients with chronic conditions (back pain, arthritis, fibromyalgia, and chronic widespread pain) generally have a two- to eight-fold greater likelihood of being diagnosed with a depressive disorder. ${ }^{68}$ Meta-analytic data confirmed the pain-reducing properties of antidepressants (vs placebo) in chronic back pain patients. ${ }^{69}$ Importantly, once a cycle of chronic or recurrent pain and negative affect (as in AD subjects) has developed, it might be difficult and clinically irrelevant to determine the current causal relationship between the two conditions. ${ }^{33}$

Among the various emotional correlates of pain, significant attention is now being directed to the variably defined theoretical concept of emotion regulation. In a longitudinal study, Paquet et $\mathrm{al}^{56}$ found that increased affect regulation was related to lower levels of pain intensity. Ruiz-Aranda et $\mathrm{al}^{36}$ showed that pain-free women scoring high in the selfperceived ability to use positive thinking to repair negative mood, reported less sensory and affective pain during the CPT procedure. Importantly, once the experimental task was over, the negative impact of pain induction on mood was less severe in those scoring high in emotional repair. These results are consistent with the other studies showing that higher emotional repair is associated with lower perception of pain. ${ }^{35,56}$

Our results have clinical implications. Emotional dysregulation is a significant correlate of alcohol use disorders, 
even in the absence of chronic pain, and drinking alcohol is commonly used by patients as an ineffective self-medication strategy for both managing pain ${ }^{70}$ and coping with negative affect. ${ }^{71}$ Growing research data suggest common underlying neurobiological mechanisms for chronic pain and addiction, including reward deficiency and antireward processes, incentive sensitization, and aberrant learning. ${ }^{15}$ As noted by Navratilova and Porreca ${ }^{16}$ chronic pain is a constant challenge for relief and can suppress or surpass other emotions, including natural rewards, leading to negative affect and anhedonia (as a reflection of reward deficiency). These negative affective states supported with the pain-induced dysregulation of reward/reinforcement circuitry may lead to excessive substance use and possibly, for some vulnerable individuals, contribute to the development of addiction. ${ }^{38}$

Recent preliminary findings revealed that deficits in utilizing and regulating emotions were an independent predictor of relapse in AD patients, ${ }^{7}$ whereas chronic pain was shown to be associated with worse pain-related and substance-related outcomes among adults treated for substance use disorders. ${ }^{13,14,72}$ These observations underlie the clinical significance of further studies on emotional competencies and pain in AD individuals. Given that 1) pain is a highly prevalent and problematic comorbidity in addiction treatment settings and 2) emotional regulation deficits are a significant correlate of both pain and $\mathrm{AD}$, it is reasonable to develop and test therapeutic strategies to improve emotional skills in patients with this comorbidity. The efficacy of psychological interventions targeted at reducing pain and improving functioning in persons with a broad spectrum of pain-related conditions has been demonstrated. ${ }^{73,74}$ However, these treatments have not been well tested in those with AUDs. Mindfulness has been suggested as a potentially beneficial therapy for chronic pain, ${ }^{74}$ and has also been used for relapse prevention in $\mathrm{AD}$ patients. ${ }^{75}$ Our data suggest that affect regulation skills training might reduce negative affect and its effect on pain intensity.

The results of our study need to be interpreted with caution because of several limitations. First, the cross-sectional design of the study precludes any conclusions regarding causation and/or directionality of the revealed associations, specifically, whether higher depressive or anxiety severity leads to greater self-reported pain or the painful experience generates higher negative affect, with the mediating effect of emotion regulation. Our findings should be confirmed within the experimental design of longitudinal observations. Moreover, our single-item, self-report measure of pain intensity in the previous 4 weeks is unidimensional, albeit utilized in other studies. ${ }^{12,76,77}$ It does not assess for the perceptual threshold, cause, location, or type of pain as well the specific context for its chronicity, origin, or continuation into the present. Except for the exclusionary criterion of opioid use, the data on the utilization of other pain management strategies such as nonsteroidal anti-inflammatory drugs or physical therapy, in the group of $\mathrm{AD}$ patients with moderate or greater pain, were not available. Finally, our study group was confined only to patients who entered inpatient treatment for $\mathrm{AD}$, which may not be representative of the broader population of individuals with $\mathrm{AD}$ and comorbid pain syndromes.

\section{Conclusion}

The results of the current study extend previous findings and suggest that emotion regulation deficits are related to severity of self-reported pain in AD subjects. Comprehensive psychotherapeutic interventions focusing on the improvement of mood regulation skills might improve the effectiveness of the treatment of $\mathrm{AD}$ patients with the comorbid pain symptoms.

\section{Acknowledgments}

This study was supported by grants from the National Science Centre (2012/07/B/HS6/02370; principal investigator [PI]: M Wojnar), Polish Ministry of Science and Higher Education (2P05D 004 29; PI: M Wojnar), and National Institute on Alcohol Abuse and Alcoholism (R21 AA016104; PI: KJ Brower).

The preliminary results from this paper were presented at the 15th European Society for Biomedical Research on Alcoholism Congress, 12-15 November, 2015, Valencia, Spain, as a conference talk with interim findings. The abstract has been published. ${ }^{78}$

\section{Disclosure}

The authors report no conflicts of interest in this work.

\section{References}

1. Castellano F, Bartoli F, Crocamo C, et al. Facial emotion recognition in alcohol and substance use disorders: a meta-analysis. Neurosci Biobehav Rev. 2015;59:147-154.

2. Donadon MF, Osorio Fde L. Recognition of facial expressions by alcoholic patients: a systematic literature review. Neuropsychiatr Dis Treat. 2014;10(5):1655-1663.

3. Thorberg FA, Young RM, Sullivan KA, Lyvers M. Alexithymia and alcohol use disorders: a critical review. Addict Behav. 2009;34(3):237-245.

4. Mayer JD, Salovey P. What is emotional intelligence? In: Salovey P, Sluyter DJ, editors. Emotional Development and Emotional Intelligence: Educational Implications. New York, NY: Basic Books; 1997:3-34.

5. Peterson K, Malouff J, Thorsteinsson EB. A meta-analytic investigation of emotional intelligence and alcohol involvement. Subst Use Misuse. 2011;46(14):1726-1733.

6. Kun B, Demetrovics Z. Emotional intelligence and addictions: a systematic review. Subst Use Misuse. 2010;45(7-8):1131-1160. 
7. Kopera M, Jakubczyk A, Suszek H, et al. Relationship between emotional processing, drinking severity and relapse in adults treated for alcohol dependence in Poland. Alcohol Alcohol. 2015;50(2):173-179.

8. Berking M, Margraf M, Ebert D, Wupperman P, Hofmann SG, Junghanns K. Deficits in emotion-regulation skills predict alcohol use during and after cognitive-behavioral therapy for alcohol dependence. J Consult Clin Psychol. 2011;79(3):307-318.

9. Subramaniam M, Vaingankar JA, Abdin E, Chong SA. Psychiatric morbidity in pain conditions: results from the Singapore Mental Health Study. Pain Res Manag. 2013;18(4):185-190.

10. Von Korff M, Crane P, Lane M, et al. Chronic spinal pain and physicalmental comorbidity in the United States: results from the national comorbidity survey replication. Pain. 2005;113(3):331-339.

11. Katon W, Egan K, Miller D. Chronic pain: lifetime psychiatric diagnoses and family history. Am J Psychiatry. 1985;142(10):1156-1160.

12. Potter JS, Prather K, Weiss RD. Physical pain and associated clinical characteristics in treatment-seeking patients in four substance use disorder treatment modalities. Am J Addict. 2008;17(2):121-125.

13. Caldeiro RM, Malte CA, Calsyn DA, et al. The association of persistent pain with out-patient addiction treatment outcomes and service utilization. Addiction. 2008;103(12):1996-2005.

14. Jakubczyk A, Ilgen MA, Kopera M, et al. Reductions in physical pain predict lower risk of relapse following alcohol treatment. Drug Alcohol Depend. 2016;158(1):167-171.

15. Elman I, Borsook D. Common brain mechanisms of chronic pain and addiction. Neuron. 2016;89(1):11-36.

16. Navratilova E, Porreca F. Reward and motivation in pain and pain relief. Nat Neurosci. 2014;17(10):1304-1312.

17. Egli M, Koob GF, Edwards S. Alcohol dependence as a chronic pain disorder. Neurosci Biobehav Rev. 2012;36(10):2179-2192.

18. Koob GF, Le Moal M. Neurobiology of Addiction. Amsterdam; Boston: Elsevier Academic; 2006.

19. Price DD. Psychological Mechanisms of Pain and Analgesia. Seattle, WA: IASP Press; 1999.

20. de Wied M, Verbaten MN. Affective pictures processing, attention, and pain tolerance. Pain. 2001;90(1-2):163-172.

21. Keefe FJ, Lumley M, Anderson T, Lynch T, Studts JL, Carson KL. Pain and emotion: new research directions. J Clin Psychol. 2001;57(4):587-607.

22. Villemure C, Slotnick BM, Bushnell MC. Effects of odors on pain perception: deciphering the roles of emotion and attention. Pain. 2003;106(1-2):101-108.

23. Strobel C, Hunt S, Sullivan R, Sun J, Sah P. Emotional regulation of pain: the role of noradrenaline in the amygdala. Sci China Life Sci. 2014;57(4):384-390.

24. Lumley MA, Cohen JL, Borszcz GS, et al. Pain and emotion: a biopsychosocial review of recent research. J Clin Psychol. 2011;67(9):942-968.

25. Sullivan MJ, Thorn B, Rodgers W, Ward LC. Path model of psychological antecedents to pain experience: experimental and clinical findings. Clin J Pain. 2004;20(3):164-173.

26. Bishop MD, Craggs JG, Horn ME, George SZ, Robinson ME. Relationship of intersession variation in negative pain-related affect and responses to thermally-evoked pain. J Pain. 2010;11(2):172-178.

27. Fernandez E, Milburn TW. Sensory and affective predictors of overall pain and emotions associated with affective pain. Clin J Pain. 1994;10(1):3-9.

28. Fernandez E, Turk DC. Demand characteristics underlying differential ratings of sensory versus affective components of pain. J Behav Med. 1994;17(4):375-390

29. Furlong LV, Zautra A, Puente CP, Lopez-Lopez A, Valero PB. Cognitiveaffective assets and vulnerabilities: two factors influencing adaptation to fibromyalgia. Psychol Health. 2010;25(2):197-212.

30. Smith BH, Elliott AM, Chambers WA, Smith WC, Hannaford PC, Penny K. The impact of chronic pain in the community. Fam Pract 2001;18(3):292-299.

31. Dworkin RH, Gitlin MJ. Clinical aspects of depression in chronic pain patients. Clin J Pain. 1991;7(2):79-94.
32. Bair MJ, Robinson RL, Katon W, Kroenke K. Depression and pain comorbidity: a literature review. Arch Intern Med. 2003;163(20):2433-2445.

33. Wiech K, Tracey I. The influence of negative emotions on pain: behavioral effects and neural mechanisms. Neuroimage. 2009;47(3):987-994.

34. Hamilton NA, Zautra AJ, Reich J. Individual differences in emotional processing and reactivity to pain among older women with rheumatoid arthritis. Clin J Pain. 2007;23(2):165-172.

35. Connelly M, Keefe FJ, Affleck G, Lumley MA, Anderson T, Waters S. Effects of day-to-day affect regulation on the pain experience of patients with rheumatoid arthritis. Pain. 2007;131(1-2):162-170.

36. Ruiz-Aranda D, Salguero JM, Fernandez-Berrocal P. Emotional regulation and acute pain perception in women. J Pain. 2010;11(6):564-569.

37. Ruiz-Aranda D, Salguero JM, Fernandez-Berrocal P. Emotional intelligence and acute pain: the mediating effect of negative affect. J Pain. 2011;12(11):1190-1196.

38. LeBlanc DM, McGinn MA, Itoga CA, Edwards S. The affective dimension of pain as a risk factor for drug and alcohol addiction. Alcohol. 2015;49(8):803-809.

39. APA. Diagnostic and Statistical Manual of Mental Disorders, 4th ed, Text Revision. Washington, DC: American Psychiatric Association; 2000.

40. Sheehan DV, Lecrubier Y, Sheehan KH, et al. The Mini-International Neuropsychiatric Interview (M.I.N.I.): the development and validation of a structured diagnostic psychiatric interview for DSM-IV and ICD-10. J Clin Psychiatry. 1998;59 (Supp1 20):S22-S33.

41. Folstein MF, Folstein SE, McHugh PR. "Mini-mental state". A practical method for grading the cognitive state of patients for the clinician. J Psychiatr Res. 1975;12(3):189-198.

42. Smith GE, Ross RL, Rost KM. Psychiatric outcomes module: substance abuse outcomes module (SAOM). In: Sederer LI, Dickey B, editors. Outcome Assessment in Clinical Practice. Baltimore, MD: Williams and Wilkins; 1996:85-88.

43. Zołnierczyk-Zreda D. Polska wersja kwestionariusza SF-36v2 do badania jakości życia [The Polish version of the SF-36v2 questionnaire for the quality of life assessment]. Przegl Lek. 2010;67(12):1302-1307. Polish.

44. Rosenblum A, Joseph H, Fong C, Kipnis S, Cleland C, Portenoy RK Prevalence and characteristics of chronic pain among chemically dependent patients in methadone maintenance and residential treatment facilities. JAMA. 2003;289(18):2370-2378.

45. Trafton JA, Oliva EM, Horst DA, Minkel JD, Humphreys K. Treatment needs associated with pain in substance use disorder patients: implications for concurrent treatment. Drug Alcohol Depend. 2004;73(1): 23-31.

46. Derogatis LR, Melisaratos N. The brief symptom inventory: an introductory report. Psychol Med. 1983;13(3):595-605.

47. Beck AT, Steer RA, Brown G. Brown manual for the beck depression inventory II. San Antonio, TX: Psychological Corporation; 1996.

48. Costa P, McCrae RR. NEO PI-R Professional manual. Odessa, FL: Psychological Assessment Resources; 1992.

49. Zawadzki B SJ, Szczepaniak P, Śliwińska M, editors. Inwentarz Osobowości NEO-FFI Costy i McCrae. Podręcznik do polskiej adaptacji. Warszawa: Pracownia Testów Psychologicznych PTP; 1998.

50. Saklofske DH, Austin EJ, Minski PS. Factor structure and validity of a trait emotional intelligence measure. Pers Individ Dif. 2003;34(4): 707-721.

51. Petrides KV, Furnham A. On the dimensional structure of emotional intelligence. Pers Individ Dif. 2000;29(2):313-320.

52. Castillo RC, MacKenzie EJ, Wegener ST, Bosse MJ. Prevalence of chronic pain seven years following limb threatening lower extremity trauma. Pain. 2006;124(3):321-329.

53. Demyttenaere K, Bonnewyn A, Bruffaerts R, Brugha T, De Graaf R, Alonso J. Comorbid painful physical symptoms and depression: prevalence, work loss, and help seeking. JAffect Disord. 2006;92(2-3):185-193.

54. Tsang A, Von Korff M, Lee S, et al. Common chronic pain conditions in developed and developing countries: gender and age differences and comorbidity with depression-anxiety disorders. J Pain. 2008;9(10):883-891. 
55. Jakubczyk A, Ilgen MA, Bohnert AS, et al. Physical Pain in AlcoholDependent Patients Entering Treatment in Poland-Prevalence and Correlates. J Stud Alcohol Drugs. 2015;76(4):607-614.

56. Paquet C, Kergoat MJ, Dube L. The role of everyday emotion regulation on pain in hospitalized elderly: insights from a prospective within-day assessment. Pain. 2005;115(3):355-363.

57. Strand EB, Zautra AJ, Thoresen M, Odegard S, Uhlig T, Finset A. Positive affect as a factor of resilience in the pain-negative affect relationship in patients with rheumatoid arthritis. J Psychosom Res. 2006;60(5):477-484.

58. Zautra A, Smith B, Affleck G, Tennen H. Examinations of chronic pain and affect relationships: applications of a dynamic model of affect. J Consult Clin Psychol. 2001;69(5):786-795.

59. Zautra AJ, Johnson LM, Davis MC. Positive affect as a source of resilience for women in chronic pain. J Consult Clin Psychol. 2005;73(2): 212-220.

60. Davis MC, Zautra AJ, Smith BW. Chronic pain, stress, and the dynamics of affective differentiation. J Pers. 2004;72(6):1133-1159.

61. Hamilton NA, Zautra AJ, Reich JW. Affect and pain in rheumatoid arthritis: do individual differences in affective regulation and affective intensity predict emotional recovery from pain? Ann Behav Med. 2005;29(3):216-224.

62. Loggia ML, Mogil JS, Bushnell MC. Experimentally induced mood changes preferentially affect pain unpleasantness. $J$ Pain. 2008;9(9):784-791.

63. Weisenberg M, Raz T, Hener T. The influence of film-induced mood on pain perception. Pain. 1998;76(3):365-375.

64. Zelman DC, Howland EW, Nichols SN, Cleeland CS. The effects of induced mood on laboratory pain. Pain. 1991;46(1):105-111.

65. Price DD. Psychological and neural mechanisms of the affective dimension of pain. Science. 2000;288(5472):1769-1772.

66. Blumer D, Heilbronn M. Chronic pain as a variant of depressive disease: the pain-prone disorder. J Nerv Ment Dis. 1982;170(7):381-406.

67. Gerrits MM, van Oppen P, Leone SS, van Marwijk HW, van der Horst HE, Penninx BW. Pain, not chronic disease, is associated with the recurrence of depressive and anxiety disorders. BMC Psychiatry. 2014;14(25):187.
68. Edwards RR, Cahalan C, Mensing G, Smith M, Haythornthwaite JA. Pain, catastrophizing, and depression in the rheumatic diseases. Nat Rev Rheumatol. 2011;7(4):216-224.

69. Salerno SM, Browning R, Jackson JL. The effect of antidepressant treatment on chronic back pain: a meta-analysis. Arch Intern Med. 2002;162(1): $19-24$.

70. Riley JL, 3rd, King C. Self-report of alcohol use for pain in a multiethnic community sample. J Pain. 2009;10(9):944-952.

71. Khantzian EJ. The self-medication hypothesis of substance use disorders: a reconsideration and recent applications. Harv Rev Psychiatry. 1997;4(5):231-244.

72. Larson MJ, Paasche-Orlow M, Cheng DM, Lloyd-Travaglini C, Saitz $\mathrm{R}$, Samet JH. Persistent pain is associated with substance use after detoxification: a prospective cohort analysis. Addiction. 2007;102(5): 752-760.

73. Kaiser RS, Mooreville M, Kannan K. Psychological Interventions for the Management of Chronic Pain: a Review of Current Evidence. Curr Pain Headache Rep. 2015;19(9):43.

74. McCracken LM, Vowles KE. Acceptance and commitment therapy and mindfulness for chronic pain: model, process, and progress. Am Psychol. 2014;69(2):178-187.

75. Witkiewitz K, Marlatt A. Behavioral therapy across the spectrum. Alcohol Res Health. 2011;33(4):313-319.

76. Witkiewitz K, McCallion E, Vowles KE, et al. Association between physical pain and alcohol treatment outcomes: the mediating role of negative affect. $J$ Consult Clin Psychol. 2015;83(6):1044-1057.

77. Witkiewitz K, Vowles KE, McCallion E, Frohe T, Kirouac M, Maisto SA. Pain as a predictor of heavy drinking and any drinking lapses in the COMBINE study and the UK Alcohol Treatment Trial. Addiction. 2015;110(8):1262-1271.

78. Kopera M, Suszek H, Jakubczyk A, et al. SY06, from negative affectivity to harmful behaviors - emotional processing in alcohol dependence; SY06-1, relationship between emotional intelligence and physical pain in alcohol-dependent patients entering treatment in Poland. Alcohol Alcohol. 2015;50 (Suppl 1):i7.
Journal of Pain Research

\section{Publish your work in this journal}

The Journal of Pain Research is an international, peer reviewed, open access, online journal that welcomes laboratory and clinical findings in the fields of pain research and the prevention and management of pain. Original research, reviews, symposium reports, hypothesis formation and commentaries are all considered for publication.

\section{Dovepress}

The manuscript management system is completely online and includes a very quick and fair peer-review system, which is all easy to use. Visit http://www.dovepress.com/testimonials.php to read real quotes from published authors. 